\title{
Process assessment and simulation games - Methods and software supported tools in Business Process Re-engineering
}

Terho Laakso

Researcher, *, e-mail: Terho.Laakso@hut.fi

Jussi Hakamäki,

Researcher, *, e-mail: Jussi.Hakamaki@hut.fi

Kimmo Forsberg

Researcher, *, e-mail: Kimmo.Forsberg@ @ut.fi

Riitta Smeds

Associate Professor, *, e-mail: Riitta.Smeds@hut.fi

* Addresses: Helsinki University of Technology, Faculty of Industrial Management, Otakaari 4 A, 02150 ESPOO, FINLAND, Phone 3580 4511, Fax 35804512107

\begin{abstract}
The objective of this paper is to introduce two methods and tools, process assessment and simulation games, which can be used to support business process re-engineering. Process assessment is a software supported analysis procedure to evaluate the present status of the processes. Simulation games are method for process redesign that is supported by the GAMEVIEW software. Tools will be developed as part of EUREKA TIME GUIDE -project (EU 1157). The paper is based on the research conducted at Helsinki University of Technology and in the eight Finnish pilot companies.
\end{abstract}

\section{Keywords}

Business process re-engineering, Process modeling, Self assessment, Self audit, Simulation games 


\section{INTRODUCTION}

Enterprises are becoming more and more aware of business processes, the performance of which is the basis for the overall capability of the enterprise. The evolution of the enterprise proceeds trough incremental process improvement or radical process innovations. Process improvement in general has three objectives:

1. Improve performance in key success factors.

2. Fulfill customer requirements and create customer satisfaction.

3. Accomplish the strategic needs of the company.

However, the methods and tools to support this new process management are still insufficient. TIME GUIDE aims to develop methods and supporting software to evaluate the performance of processes and to design new process solutions. In this paper, two of the TIME GUIDE tools are presented: process assessment and simulation games. Through process assessment, an enterprise gets aware of the weak points in its processes and can define a new set of performance measures that supports process structures and process thinking. Process assessment gives a starting point to the improvement work and to process re-engineering. By participative simulation games new process structures can thereafter be designed and tested.

\section{MANAGEMENT OF PROCESS IMPROVEMENT}

The improvement arises from individuals active perception of problems or a recognition of opportunities. The needed creativity and innovation can be either encouraged or discouraged by the environment. Creativity and innovation begin with a clear mental picture of an imagined future state (Barrett, 1994). This clear picture creates us a space for possible actions where the prevailing operations and procedures are allowed to be challenged.

Participation is one main principle in successful change management. When all the relevant individuals, who are engaged in an operational process, can participate in its redesign from the beginning, the jointly developed solutions are likely to be better in productivity and work satisfaction, and resistance to change can be avoided to great extent (Smeds, 1994). Participation is thus supported in the TIME GUIDE tools.

Process improvement can be seen as a system of nested cycles 'Figure 1'. In the outer slow cycle, the strengths and weaknesses of the company derived from the market needs and expectations are at first clarified. After this phase the company identifies the key process that has to be developed and how much it needs improvement. Improvement can be evolutionary (incremental) or revolutionary (radical).

In the fast inner cycle, process improvement is based on small-step-development (incremental). The process structure is usually in this case sharpened and/or the performance measurement system is developed to support better the process objectives. From our experience in the Finnish pilot companies, substantial improvements in an enterprise can be achieved by streamlining present processes and by introducing a new process oriented measurement system. This re-engineering approach will be supported by the new tools. 
Process assessment and simulation games are tools in the nested business process improvement cycles. The process assessment tool helps companies to analyze processes independently. The simulation games are used for process redesign. They visualize the problems of the present process and can be used to test new process structure.

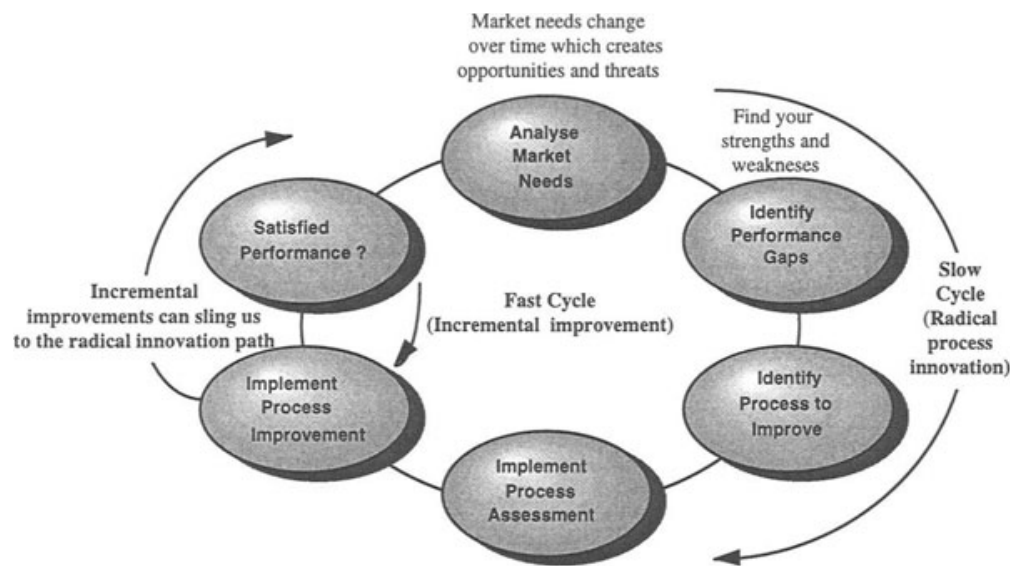

Figure 1 The nested business process improvement cycles.

\section{THE PROCESS ASSESSMENT METHOD}

The process assessment (PA) project proceeds through a sequence of seven steps 'Figure 2'. The steps are described in detail in the subsequent sections. PA focuses on the key success factors driven from customer requirements, market needs, competitors' actions and objectives of the company.

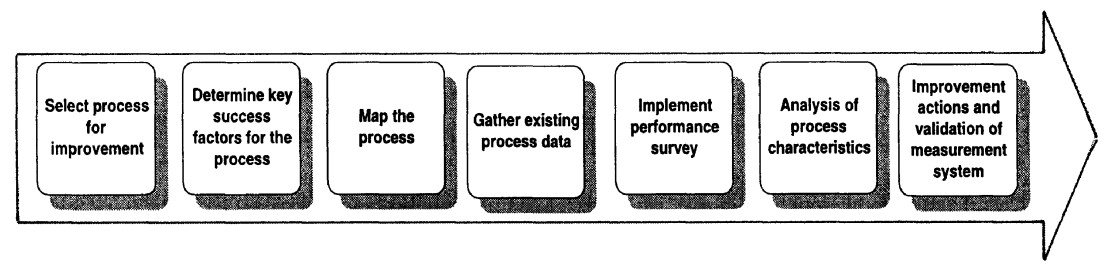

Figure 2 Framework of the process assessment procedure.

\section{Procedures to select process for improvement}

There are many methods and procedures available to identify process improvement needs of the company. The main stress should be in the requirements that come from the external environment of the company. However, internal requirements of the company should not be 
ignored, because there are activities that are important for the company, but not for customers, and vice versa.

J. Harrington (1991) listed following reasons for selecting a process for improvement:

- external customer problems and/or complaints;

- internal customer problems and/or complaints;

- high cost processes;

- long cycle time processes;

- there is a better-known way (benchmarking, etc.);

- new technologies are available;

- management direction based on an individual manager's interest.

\section{Determine Key Success Factors for Processes}

Key success factors (KSF) are important characteristics of the outputs of the processes. They are factors that have the most influence on the success of the company. Usually, KSFs are external customer-driven, but in cases where a process does not have an external customer interface, the factors must be defined by an internal customer.

One of the essential precondition for realizing key success factors in a company are an appropriate target setting system. We have to convert KSF's to measurable units. Thus, we can create a link between the overall objectives of the company and the objectives of any single activity in a process.

\section{Process mapping}

From our experience in the Finnish pilots the process mapping sessions have had a strong impact on understanding the inner activities of, and relationships between, studied processes. The process map also facilitates communication between people and it helps to share a common view about what is going on in the process.

We would like to point out some general aspects, which should be taken into account in process mapping notations. The notation should have a visual power to depict clearly different processes, but at the same time the notation should be easy to learn. Ease of learning may be viewed differently by the people who draw process maps and by those who read them (Kontio 1994). While the map is a tool for communication, the main emphasis of the notation should be on readability and on straightforwardness.

While mapping the process, we should aim at a sufficient level of description. Otherwise we can easily end up to describe the process in more and more detailed parts. This results in a complex model that is hard to understand, and most of our resources have been spent to the description alone. There is no more strength and motivation left for the improvement and redesign. People do require quick visible responses and actions in order to maintain their enthusiasm for the change project.

\section{Process data gathering}

Actual process data gathering begins after the mapping sessions. It can turn out to be a quite arduous job. The information system of the company does not normally support the process point of view, but is usually build up around traditional functional structures. 
Our approach to data gathering begins by becoming familiar with the present reporting and measurement system, because it offers a good entry point to reality of the process. We discover at once to which extent present reports and measures are supporting the objectives of the process.

If a wide variety of products is produced in one process, the usage of time and other resources varies heavily depending on product type. In this situation we should focus on a few case products that help us to restrict the scope of the work and at the same time give us reliable information about the process. Overall averages do not give much information about real process performance. The strength of case products are also that we get concrete clues to follow.

\section{Performance survey}

The performance survey gathers the employees' subjective believes and opinions about process and company performance. The survey as such commits people to improvement work by involving them into the project at an early stage. Most important, however, is to find out the possible differences in the individual performance estimates. They might reveal a great need for process improvement.

The performance survey in the process assessment project is tailored for each process and each company individually. The survey is partly based on the process map and partly on questions classified according the general process models. The main parts of the questionnaire are:

1. general information gathering;

2. consciousness of key success factors of the process;

3. evaluation of activities;

4. analysis of few selected activities that are most important for the respondent;

5. general system evaluation.

\section{Analysis of process characteristics}

In the previous section, the qualitative and subjective performance survey and its objectives were introduced. Here we are concentrating on figure-based analyses. They are performed to find out the status of the process, using measurement system information or other means of documentation. Three types of analyses may be implemented in this phase of PA; time-based, cost-based and quality-based analyses. What types of analyses are used depends totally on the improvement objectives of the company.

Time has become a more and more important competitive factor and time-based analyses have become very powerful tools in process improvement. Time is an exact factor, and usually time-based data is well documented in companies. Time-based data gives a good picture how a process is functioning, and where time really adds value during the process.

Cost-based analyses are often difficult, because many costs are not chargeable to individual categories e.g. activities. This is particularly true of many overhead costs. Some form of allocation system (such as activity-based costing) must be used to employ cost-based analyses effectively. Many patterns are used, and companies vary appreciably in their format of costbased analyses. Regardless of the difficulties involved, cost-based analyses are seen as a necessary element in the control and evaluation of processes. 
Quality-based analyses help companies to identify their quality improvement needs in processes. The occurrence of different defects in time and quantity is listed and based on that information the cost of poor quality is calculated. Identifying cause-effect relations for defects is supported by the tool.

\section{Improvement actions}

As a result of the PA procedure the company should now have a clear picture what is happening in the assessed process. This consciousness is needed in the next phase, which is more problem solving oriented. The improvement work can direct its attention e.g. to:

- re-design of process structures;

- re-thinking of procedures;

- updating the performance measurement system;

- utilization of new technology;

- building and utilization of new competence;

- re-structuring company polices and organization.

The process assessment tool helps also to validate present measurement practices and to find new process oriented measures. These new measures do not compete with the overall performance management system. Instead, they must be integrated to the overall system in order to support the measurement of the daily operations.

To help people in selecting valid measures for processes the libarry of measures and drivers is introduced. It is a structured catalog of reasonable measures to support a new process oriented management paradigm. This catalogue is realized as a database in the PA tool, and possible measures can be found by using different search keys. The librarry serves thus as an idea bank when new process oriented measures are generated and validated.

\section{SIMULATION GAMES}

\section{The rationale of simulation games in business process re-engineering}

Simulation games are a powerful means to redesign process structures and to aid in their implementation. In a business process re-engineering project, simulation games can thus be used as a natural next step after the process assessment procedure. Process assessment gives an important input to the redesign phase: it helps in the selection of the target process, and it gives concrete measures and restructured objectives for the redesign task.

The virtue of social simulation games is that they bring together all those organizational variables that are crucial for process improvement: the tasks and activities, the formal and informal information flows, and individuals in their actual work roles. These participative games create the holistic understanding of the process that is needed in successful and efficient improvement work (Smeds 1994).

Simulation games can be used as a rapid process prototyping method in a participative manner. The results of simulation games in process restructuring have so far been excellent (Ruohomäki 1994, Smeds 1994, Smeds and Haho 1995a, 1995b). The new, game-designed 
processes are superior in both efficiency and human-orientedness, and the total lead-time of change could be considerably shortened.

Simulation games are applicable in almost every kind of processes. They can e.g. be used in redesigning the whole order to delivery chain or they can focus only on the production process.

The six main phases of the method are depicted in 'Figure 3'. The different phases in the framework are described in more detail in the text below.

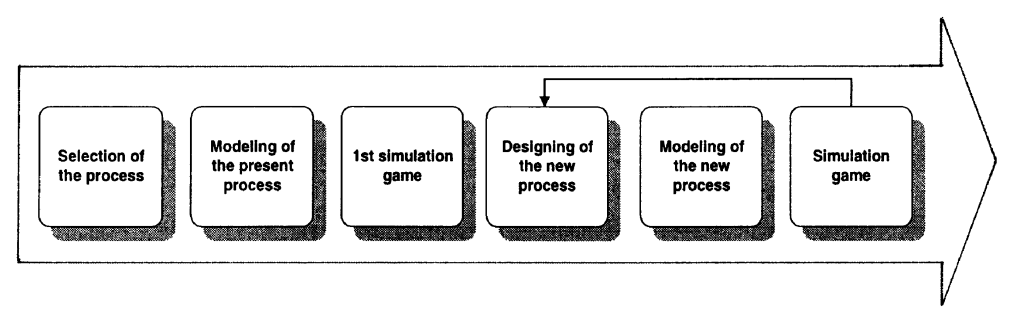

Figure 3 The main phases of the simulation game method.

\section{Modeling of the present process}

The modeling work can start after the target process for redesign has been selected (discussed in section 3). The modeling of the present process is a team effort and is done by using the wall chart technique. These modeling sessions are led by an external or an internal facilitator. The team involved is a mixture of employees that are familiar with the process.

The objectives for redesign direct the modeling work. The model can describe the general process flow, or it can be built on a more detailed level by using selected case examples. The case method is very useful e.g. in make-to-order processes. The simulation game itself is usually played using real case history material.

The basic model is a flow chart where the process is depicted through a set of activities and material and information flows. The model can include also information about actors, functions, description of activity and resources. The model is produced by the GAMEVIEW software, that is developed in TIME GUIDE project to support the simulation games.

\section{First simulation game}

The first simulation game visualizes to all participants the present state of the process. The game provides a common understanding of the whole chain with its strengths and weaknesses. It shows the interdependence between different departments and activities and stresses out the importance of cooperation and communication. During the game, concrete improvement proposals and ideas come up for further discussion.

Before the game, the participants and their roles have to be decided. The actors have an active role during the game. They play their actual real working roles. Questions about the problems in the process can be discussed together, as they rise. The observers follow the game and make notes of improvement ideas and questions that come up during the game. To observe a simulation game is often a very useful experience e.g. for managers and system designers. The number of the actors can be around 20 , and an adequate number of observers is around five. 
The game room should resemble in its lay-out the real departments or functions. The room should be equipped with different kinds of gaming material: a big process flow chart, documents used in the real process, raw materials and products (or scale models) handled in the process. The gaming material needs not to be very sophisticated. The most important issue is that there is something concrete to depict the flow of information and material in the process, not just the verbal explanation.

The basic idea of the simulation game is simple. The game follows the process flow that is depicted in the flowchart on the wall. The documents and the objects representing the raw material or the products are passed over from actor to actor like in the real process and each actor explains to the others their own tasks.

During the game, the other actors and the observers are free to ask about unclear things and make their own comments. The problems, improvement ideas and other comments that appear during the game, are documented on stickers by the actors and observers. These stickers are then attached to the flowchart on the wall.

The game is led by an external or internal facilitator who guides the game by making questions and comments. The facilitator directs the discussion in order to achieve the predefined objectives of the game.

After the game, a short debriefing workshop is organized where the problems and the development ideas that arise during the game are discussed and summarized.

\section{Designing and modeling the new process}

The experiences and documents from the first simulation game are used in smaller change project groups to design the new process structure. The design phase should not concentrate too much on resolving every single problem that came up in the first game. Rather, the whole process structure should be scrutinized and redesigned. When the whole process structure is reshaped, many of the minor problems that appeared in the first simulation can be eliminated.

The model of the new process must be more precise than the first model. Whereas in the first game the actors play in their own work roles, the second round is now based on the hypothetical future process. In other respects the preparation for the second game is a repetition of the first game.

\section{The second and subsequent simulation games}

The purpose of the second simulation game is to test the functionality of the designed process before implementation. The game provides also a learning experience to the actors as well as to the observers. The second game goes mainly like the first one. However, if the actors are not familiar with the designed process, the role of the facilitator is more critical. He or she must explain the new process structure and how it affects the actor's roles. The second game could be more structured than the first one. This means that the participants are not allowed to make so many questions and comments. The questions and comments are however written on the stickers and attached to the flow chart on the wall and summarized and discussed after the game.

The results of the second game are used as an input for further development of the process. Subsequent simulation games can be used to experiment different process alternatives before the final choice. Thereafter simulation games can be used for employee training before the actual implementation of the new process. 


\section{The GAMEVIEW software}

GAMEVIEW is a software tool that is developed in TIME GUIDE to support the simulation games. It can be used for business process modeling, process visualization and process information gathering. The software produces automatically some of the material needed in the simulation game, and it also supports the documentation of the problems, improvement ideas and other comments that arise during the game. The models stored in the software can be analyzed using different kinds of views. These views can be either graphical or text based reports. The reports and the views of the software can e.g. be used as process documents for the company's quality manual.

\section{CONCLUSIONS}

The existing tools to support process re-engineering activities are still insufficient. The TIME GUIDE project aims to develop as a part of overall methodology tools and methods to evaluate the performance of processes and to design new process solutions. In 'Figure 1' we introduced the main phases of the process improvement cycle. Trough process assessment, an enterprise gets aware of the weak points in its processes and can define a new set of performance measures that supports process structures and process thinking. After the process assessment procedure, the company has a clear picture what is happening in the assessed process. This consciousness is needed in process redesign. Important inputs to the redesign phase are the concrete measures and restructured objectives, which provide the "red thread" for the restructuring.

Simulation games can be seen as a natural next step after the process assessment procedure in the business process improvement cycle. They allow a rapid participative process prototyping for business process redesign. The new, game-designed processes have turned out to be excellent in both efficiency and human-orientedness, and cost savings in implementation have been considerable.

\section{REFERENCES}

Barrett, J. (1994) Process Visualization Getting the Vision Right Is Key. Information System Management, Spring 1994, 14-23.

Bredrup, H. (1995) Productivity studies in Performance Management: A Business Process Benchmarking Approach. (editor: Rolstad=E5s, A.) Chapman \& Hall, London, UK, pp. 17 43.

Colom, J. and Smeds, R. and Kleinhans, S. and Doumeningts, G. (1994) The role of benchmarking in the management and change process: some reflections from the TIME GUIDE project. In: Asbjörn Rostadås (ed.) Benchmarking - Theory and Practice, Chapman \& Hall, London, 1995, 51-62.

Crosby, P. (1990) QES-Course material. Winter Park, Creative Factory, Inc. 146. 
Harrington, H J (1991) Business Process Improvement. Quality Press, McGraw-Hill, Inc. New York, 267.

Kontio, J. (1994) Software Process Modeling: A Technology Review and Notation Analysis, Working document, Nokia Research Center, 50.

Moseng, B. and Bredrup, H. (1993) A methodology for industrial studies of productivity performance. Journal of Production Planning and Control, 4 (3).

Ruohomäki, V. (1994) Participative development and organizational learning with work flow game. In: Vartiainen, M. and Teikari, V. (eds.) Working papers of the third Otaniemi Dresen Workshop, 16-17.12.1993, Report Series of Industrial Economics and Industrial Psychology Helsinki University of Technology, No 157, TKK Offset, Espoo, 63-75.

Smeds, R. (1994) Managing Change Towards Lean Enterprises. International Journal of Operations and Production Management, Vol. 14/3, 66-82.

Smeds, R. and Haho, P. (1995a) Tailored order-to-delivery process simulation game. In: Jens Riis (ed.) Simulation Games in Production Management. Chapman \& Hall, London, 1995 (in press).

Smeds, R. and Haho, P. (1995b) Simulation games in business process re-engineering. In: Danny Saunders (ed.) The simulation and Gaming Yearbook Volume 3: Games and Simulations for Business. Kogan Page, London, 1995, 246-253 (in press).

\section{BIOGRAPHY}

Terho Laakso received his Lic. Tech in information processing science at Helsinki University of Technology in 1993. After his M.Sc.(Eng.) graduation in 1989 he worked as a system engineer and quality manager in Schneider Electric Oy for five years. Currently Terho Laakso is researcher at HUT and undertaking research on business process re-engineering in TIME GUIDE project.

Jussi Hakamäki, M.Sc.(Eng.) graduated from Helsinki University of Technology in 1993. He is currently working as a researcher at HUT in TIME GUIDE project. His special interest is the use of simulation games in business process improvement and re-engineering.

Kimmo Forsberg received his M.Sc.(Eng.) in industrial management at Tampere University of Technology in 1993. Since then he has worked as a researcher at HUT. His special interests are business process improvement and related issues of industrial buying behavior.

Riitta Smeds is Associate Professor at Helsinki University of Technology, Department of Industrial Management. Her current research interests concern enterprise evolution, technology strategy, management of change projects in enterprises and enterprise networks, business process re-engineering, management of innovations, implementation of new technoorganizational systems, participative modeling and simulation for business process redesign. She is currently leading the Finnish part of the two year EUREKA project TIME GUIDE "Guiding the evolution of industrial enterprises", as well as the EUREKA project SOFTMATCH "Social simulation method for the management of techno-organizational change". 